\title{
What Are the Metaphors We Live by?
}

\author{
$\mathrm{Xiu} \mathrm{Yu}$ \\ Qingdao University of Science \& Technology, Qingdao, China
}

\begin{abstract}
This paper aims to have a brief study on the conceptual metaphor theory. By discussing the philosophical basis, the nature and the working mechanism of conceptual metaphor, people can know that metaphors are the ways for people to conceptualize understand the world better.
\end{abstract}

Index Terms - conceptual metaphor theory, experientialism, conceptual metaphor, working mechanism

\section{INTRODUCTION}

With the rising of the second trend of the cognitive science in the early 1970s, the study of metaphor has extended its territory to cognitive linguistics. Different from the traditional perspective, the cognitive approach regards metaphor as a way of structuring abstract thinking and a means of constructing people's experiences (e.g., Gibbs, 1994; Lakoff and Johnson, 1980; Lakoff and Turner, 1989; Steen, 1994; Sweetser, 1990; Turner, 1987) (Xiu Yu, 2012). Along with the development of cognitive linguistics, the publication of Lakoff and Johnson's Metaphors We Live By (1980) brought a turning point in the study of metaphor. Their main point, which was later described as "conceptual metaphor theory", stated that metaphor was not a deviation of language, instead, it was a cognitive tool for people to conceptualize the objective world. "Metaphor is pervasive in everyday life, not just in language but in thought and action" (Lakoff and Johnson, 1980, p.3). People's ordinary conceptual system in terms of which they think and act, is fundamentally metaphorical in nature (Lakoff and Johnson, 1980).

Based on the above-mentioned revolutionary statements, the paper aims to make a brief analysis of conceptual metaphor theory in three sections. The first is the introduction. The second section chiefly elaborates on the philosophical basis of the theory (i.e. embodied realism) in comparison with objectivism and subjectivism. The last one, which is further divided into three parts, mainly deals with the important aspects of conceptual metaphor.

\section{PhilosophicAl BASIS}

"Living a human life is a philosophical endeavor. Every thought we have, every decision we make, and every act we perform is based upon philosophical assumptions so numerous we couldn't possibly list them all" (Lakoff and Johnson, 1999, p.9). In fact, philosophy is the most fundamental science that has infused into every aspects of human culture for centuries. In terms of linguistics, therefore, it is quite necessary and reasonable for the dissertation to trace the philosophical assumptions upon which different linguistic theories are based so that a profound understanding of metaphor can be achieved.

\section{A. Different Philosophical Theories and Their Views on Language and Metaphor}

1. Objectivism and the classical claims

Objectivism, which is the basis of objectivist tradition in philosophy, has been dominating Western culture ever since the classical period. Its view on the absolute, objective truth has a widespread effect on most of the social subjects, especially in the realms of science, law, government, economics and so on. The followings are a brief generalization of the ideology of objectivism (Lakoff, 1987).

a. The world consists of a variety of objects, which have certain inherent propertities independent of human beings. People's understanding of the world is processed in terms of categories and concepts.

b. The reality is always objective and the truth is absolute. In order to fit reality, people need direct and precise words. Therefore, any kind of rhetorical language, such as metaphor, should be avoided.

c. Subjectivity, along with all the imaginative aspects of human psychology are not of truth. They can be dangerous and unfair. Thus, they should be ignored.

Along with the theory of objectivism, a classical concept of categorization in the study of language has blossomed. According to this categorization, the concepts are divided into fixed categories based on the objective reality. Since the categorization is independent of human mind absolutely, any human psychological aspects of the language, including metaphor, should be avoided. Otherwise, the truth and reality will be violated (Taylor, 1995).

In his Republic, Plato has expressed his anxiety and suspicion towards all the poetic writings. He maintains that truth is absolute and metaphor or other rhetoric approaches should be banned as they would blind people's eyes from the objective reality (Cameron and Low, 1999). Unlike his teacher, Aristotle places a positive value on poetry and metaphor. According to Aristotle, people actually learn and understand things better through metaphor. Though Aristotle's positive statement on metaphor is very unique at that time, the nature of metaphor, in Aristotle's eyes, is merely a figure of 
speech used in rhetorical style (Hawkes, 1980).

2. Subjectivism and the romantic tradition

In contrary to objectivism, the theory of subjectivism puts emphasis on the importance of the human consciousness. It claims that people's experience is not built upon any external constraints of meaning and truth. Subjectivism plays an important role in the domains of art and religion. In general, the main assumptions of subjectivism include the following (Lakoff and Johnson, 1980):

a. People's senses and intuitions are the only things that can be trusted when dealing with practical activities. Personal feelings, aesthetic sensibilities and so on are far more important than truth and reason.

b. The language of imagination, especially metaphor, is necessary for expressing the unique and significant aspects of people's experience.

The theory of subjectivism exercises its great influence on the development of the Romantic tradition. Many outstanding figures of Romantism, such as Shelley, Wordsworth and Coleridge, put emphasis on human feelings and psychological experiences and view language, especially metaphor, to be of some creative significance rather than a reflecting function.

3. Problems with objectivism and subjectivism

The fact that both objectivism and subjectivism have great influence on Western culture suggests that both of them have served some important function. However, neither of them is flawless. In spite of their respective disadvantages, objectivism and subjectivism share a common weakness, that is, neither of them has realized the interaction between physical reality and psychological imagination.

From what has been expounded, the problem of objectivists is that they fail to give an account of the way that people understand and conceptualize the world. That is to say, "what objectivism misses is the fact that understanding, and therefore truth, is necessarily relative to our conceptual systems and that it cannot be framed in any absolute or neutral conceptual system" (Lakoff and Johnson, 1980, p.194).

On the contrary, the central shortcoming of subjectivists is that they believe imaginative understanding is totally unconstrained. In other words, "what subjectivism specifically misses is that our understanding, even our most imaginative understanding, is given in terms of a conceptual system that is grounded in our successful functioning in our physical and cultural environments" (Lakoff and Johnson, 1980, p.194).

\section{B. Experientialism: Philosophical Basis of Conceptual Metaphor Theory}

With the development of cognitive science and cognitive linguistics, an empirically responsible philosophy--experientialism, which is later described as "embodied realism" in Philosophy in the Flesh (Lakoff and Johnson, 1999), comes into being (Xiu Yu, 2012).

The experientialist view suggests that "experience is the result of embodied sensorimotor and cognitive structures that generate meaning in and through our ongoing interactions with our changing environments. Experience is always an interactive process, involving neural and physiological constraints from the organism as well as characteristic affordances from the environment and other people for creatures with our types of bodies and brains" (Johnson and Lakoff, 2002, p248). Therefore, meaning arises, not just from the internal structures of the organism, nor only from the outside world, but rather from an interaction between the organism and environment (Xiu Yu, 2012).

For example, container, as one of the most basic objects, is frequently used in people's everyday life. Similarly, the numerous concrete objects that have visible boundaries in people's physical experience are also regarded as a type of "container", like clothes, room, cup, cars and sometimes, even people's bodies. For instance, moving from one room to another is moving from one container to another. Since people are in constant contact with such objects by going in and out of these concrete boundaries, people's encounter with containment and boundedness is one of the most pervasive features of their bodily experience. As a matter of fact, it is through that universal experience of bounding surface and in-out orientation that people form a particular kind of metaphor, i.e. CONTAINER METAPHOR, as reflected in the following examples:

E.g.

The park is coming into view.

I pour the coffee into a cup.

The car is out of sight.

Try to get out of the commitments.

We are enveloped in darkness.

Do get the idea out of your head.

He takes out a bottle of milk from the refrigerator.

All the expressions above are so commonly used that human beings think that they are self-evident. People usually ignore that the expressions are metaphors because the mapping of CONTAINER experience has become one of their inner unconscious mechanism of thinking.

Obviously, the experientialist view on metaphor, which differs from both objectivism and subjectivism, holds that metaphor is one of the basic mechanisms people have for understanding one kind of experience in terms of another. In other words, the experientialist approach bridges the gap between objectivism and subjectivism. Thus, embodied realism "is not a philosophical doctrine tacked onto the theory of conceptual metaphor. It is the best account of the 
grounding of meaning that makes sense of the broadest range of converging empirical evidence that is available from the cognitive sciences" (Johnson and Lakoff, 2002, p.249).

\section{CONCEPTUAl MetAPHOR}

\section{A. The Nature of Conceptual Metaphor}

In Metaphors We Live By, Lakoff and Johnson (1980) state that human conceptual system is metaphorically structured and defined. According to them, conceptual metaphor is a system of metaphor that lies behind much of everyday language and forms everyday conceptual system, including most abstract concepts (Xiu Yu, 2011). Metaphor, in essence, is "understanding and experiencing one kind of thing in terms of another" (Lakoff and Johnson, 1980, p.5). Concerning the nature of metaphor, Lakoff and Johnson (1980) denotes the following details:

a. Metaphor is primarily conceptual in nature. It is not merely a matter of words, but also a matter of thought.

b. The metaphorical linguistic expression is a surface manifestation of conceptual metaphor.

c. Metaphor is the main cognitive mechanism through which abstract concepts are comprehended and abstract reasoning is performed.

d. Metaphor allows mankind to understand a relatively abstract or inherently unstructured subject matter in terms of a more concrete or more highly structured subject matter. One cannot think abstractly without thinking metaphorically.

To elucidate the conceptual nature of metaphor, the author begins with the concept TIME and the conceptual metaphor TIME IS MONEY, which is reflected in a variety of linguistic expressions in English.

TIME IS MONEY

You're wasting my time.

I don't have time to give you.

How do you spend your holiday?

That meeting costs me two hours.

He is running out of time.

I've invested a lot of time in painting.

Do put aside some time for your paper.

Please budget your time reasonably.

You should save enough time to do the next project.

She lost a lot of time when she was in university.

From the metaphor TIME IS MONEY, people can notice clearly that they talk about time in terms of money. The metaphor is not arbitrary, instead, it is rooted in Western culture. Since work is typically associated with the time it takes and the time is precisely quantified, time in Western culture is not only a limited resource but also a precious and valuable commodity just like money. Accordingly, it is very natural for people to make use of everyday experience with money to structure and comprehend the abstract concept TIME.

One more example to clarify the nature of metaphor, ARGUMENT IS WAR.

ARGUMENT IS WAR

Your claims are indefensible.

He attacked every weak point in my argument.

His criticisms were right on target.

I demolished his argument.

I've never won an argument with him.

You disagree? Okay, shoot!

If you use that strategy, he'll wipe you out.

He shot down all of my arguments.

(Lakoff and Johnson, 1980, p.4)

These expressions can be often found in people's everyday conversations. By using ARGUMENT IS WAR metaphor, people can use the concept of WAR to account for various aspects of an ARGUMENT. For example, in the war, people fight with their opponents; they attack enemy's position and defend their own; they may lose or win; they plan and use strategies; they can abandon a position or take a new attack. All these actions in the war are applied to talk about an argument in people's conversation.

In fact, all the expressions listed here are mostly conventionalized concepts that have stored in each individual's mind. That is to say, people not only understand things metaphorically, but also construe the concepts of things with the help of conceptual metaphor.

To sum up, people usually employ concrete experience as an instrument to structure and comprehend the relatively abstract concept. So to speak, metaphor is a figure of thought.

\section{B. The Classification of Conceptual Metaphor}

Though conceptual metaphors share the same basic common feature of being a tool of conceptualization, they are different from each other. Generally, the classification of conceptual metaphors can be made through two different aspects: the classification in terms of frequency level and the classification in terms of experiential bases. 
1. The classification in terms of frequency level

In light of the frequency level, conceptual metaphor can be divided into two categories: conventional metaphor and new metaphor.

a. Conventional metaphor

According to Lakoff and Johnson (1980, p.139), "conventional metaphors are metaphors that structure the ordinary conceptual system of our culture, which is reflected in our everyday language".

The so-called "conventional" applies at both the conceptual and linguistic levels (Lakoff and Turner, 1989). At the conceptual level, a metaphor is conventional to the extent that it is automatic, effortless, and generally established as a mode of thought among members of a linguistic community. At the same time, "conventional" also applies to the connection between the conceptual and linguistic levels. When people speak of the degree to which a conceptual metaphor is conventionalized in the language, they mean the extent to which it underlies a range of everyday linguistic expressions.

Conventional metaphor has infused into every aspect of the society. Without realizing that a metaphorical conceptualization is being processed, people can easily understand and use the expressions such as "He is in trouble now", "I've got a stomachache", etc.

b. New metaphor

New metaphors, or novel metaphors, are different from conventional metaphors in that they are beyond social conventions and "are capable of giving us a new understanding of our experience" (Lakoff and Johnson, 1980, p.139). The power of new metaphors is to create a new reality rather than simply to give mankind a way of conceptualizing a preexisting reality as conventional metaphors do (Lakoff and Johnson, 1980). Therefore, new metaphors play a very important role in imagination and creation of new meaning.

New metaphors use the mechanisms of conventional and everyday thought in extraordinary ways. That is, what makes the new metaphors noticeable and memorable is that new metaphors extend them, elaborate them, and combine them in ways that go beyond the bounds of ordinary modes of thought and beyond the automatic and unconscious conventional use of metaphor ( Lakoff and Turner, 1989). So to speak, the study of new metaphor is an extension of the study of conventional metaphor. Conventional metaphor is characterized by a huge system of cross domain mappings, and this system is made use of in new metaphor.

For example, the conventional metaphor DEATH IS SLEEP, is a general and ordinary metaphorical conception that views death as sleeping when people speak of someone that passed away. The mapping in this metaphor, of course, does not involve all people's general knowledge about death, but only certain aspects: inactive, inattentive and so on. However, in Hamlet's soliloquy, Shakespeare extends creatively the ordinary metaphor of death as sleeping to include elements that are not conventionally mapped--the possibility of dreaming (Lakoff and Turner, 1989):

To sleep? Perchance to dream! Ay, there's the rub;

For in that sleep of death what dreams may come?

(William Shakespeare, Hamlet, Prince of Denmark, Act III, Scene I) (Xiu Yu, 2011)

Despite the differences between new metaphor and conventional metaphor, the former makes sense of people's experience in the same way the latter does. Indeed, the general principles which take the form of conceptual mappings, apply not just to the ordinary everyday language but to much of novel poetic expressions. In other words, the generalizations governing both ordinary language and poetic metaphorical expressions are not in language, but in thought. To be specific, they are all general mappings across different conceptual domains.

2. The classification in terms of underlying structures

In terms of underlying structures, metaphors can be further divided into structural metaphors, orientational metaphors and ontological metaphors.

a. Structural metaphor

As the most frequently used metaphors of the three categories, the structural metaphors refer to those in which one concept is metaphorically structured in another one. For instance, as the following table (Table 3.1) lists, in LIFE IS JOURNEY metaphor, life is understood with some of the properties of journey structurally mapped onto the corresponding properties of life (Lakoff and Turner, 1989, p.3).

TABLE 1:

SOME STRUCTURAL MAPPINGS FROM JOURNEY TO LIFE

\begin{tabular}{|l|l|}
\hline Structural mapping & Examples \\
\hline The person leading a life is a traveller. & As we go through life, I hope we'll always be friends. \\
\hline His purposes are destinations. & Her goal in life is to get her Ph.D. \\
\hline The means for achieving purpose are routes. & You're on the right path now. \\
\hline Difficulties in life are impediments to travel. & He worked his way around many obstacles. \\
\hline Progress is the distance traveled. & He made his way in life. \\
\hline Things you gauge your progress by are landmarks. & $\begin{array}{l}\text { She came to a point in her life where she had to make a } \\
\text { difficult decision. }\end{array}$ \\
\hline Choices in life are crossroads. & There were two paths open to them. \\
\hline
\end{tabular}

Through this metaphor, people understand that life is a long-term, purposeful activity. One's goals in life are one's destinations in the journey. Difficulties in life are impediments to one's motion. In other words, the concept of LIFE is 
comprehended because it is metaphorically structured in another one: JOURNEY.

b. Orientational metaphor

Orientational metaphors are not metaphors which "structure one concept in terms of another but instead organize a whole system of concepts with respect to one another" (Lakoff and Johnson, 1980, p.14). Most of them have to do with spatial orientation: up-down, in-out, front-back, on-off, deep-shallow, central-peripheral. Orientational metaphors usually have a basis in people's physical and cultural experiences. For example, from the fact that drooping posture typically goes along with sadness and depression, erect posture with a positive emotional state, people gained the metaphor HAPPY IS UP, SAD IS DOWN, as in the usage of "I'm feeling up", "You're in high spirits", and "He's really low these days", etc. Similarly, from the fact that physical size typically correlates with physical strength, and the victor in a fight is typically on top, human beings obtained the metaphor HAVING CONTROL or FORCE IS UP, BEING SUBJECT TO CONTROL or FORCE IS DOWN. Expressions of these metaphors include "I do not have control over her any more", "He is in an inferior position", "She is under my control", "I'm in the high command", etc.

c. Ontological metaphor

Ontological metaphors are based on people's experience with physical objects. Their formation enables human beings to view non-physical entities such as events, activities, emotions, ideas and the like, as physical entities and substances. For example, they can allow people to process the activities such as referring, quantifying, identifying aspects, identifying causes, setting goals and motivating actions on some abstract concepts. For example:

My fear of cat makes her mad. (Referring)

He has little patience to do that. (Quantifying)

Her fame of being kind to the poor has been widely spread. (Identifying aspects)

The pressure caused him to give it up. (Identifying causes)

I went to Paris to see my best friend, Susan. (Setting goals and motivating actions)

In addition, ontological metaphors also enable people to understand some features of a physical entity in terms of another. For instance, the metaphorical concept, THE MIND IS A MACHINE, enables them to understand easily the metaphorical sentence "I'm a little rusty today". The spatial metaphor for mind (e.g. "in" one's minds, "in the back corners" of one's minds, and "call things to mind") is a good example of the general observation in talking about abstract concepts by means of using language drawn from concrete domains (Zonglin Chang, 2005).

\section{The Working Mechanism of Conceptual Metaphor}

According to Lakoff and Johnson (1980), the working mechanism of conceptual metaphors lies in the fact that conceptual metaphors are mappings across different conceptual domains, involving projections from a source domain to a target domain. They claim that (Xiu Yu, 2012):

a. Metaphorical mapping is uni-directional and asymmetric, that is, from the more concrete to the more abstract.

b. Metaphorical mapping is partial, not total, namely, the structure of the source domain is only partly projected to the structure of the target domain.

c. Metaphorical mapping is not random and arbitrary, but grounded in the body and everyday experience in the physical and cultural world.

d. Metaphorical mapping is systematic across different conceptual domains.

To account for the working mechanism of conceptual metaphor, a typical example is indispensable. In order to keep pace with the times, the author takes INTERNET IS A HIGHWAY for example.

Some years ago, the U.S. Vice President Gore exploited the INTERNET IS A HIGHWAY metaphor when he announced the Clinton administration's National Information Infrastructure initiative in December 1993. Gore is worth quoting here at length for discussion (Fuyin Li, 2004).

Today, commerce rolls not just on asphalt highways but along information highways. And tens of millions American families and business now use computers and find that the 2-lane information pathways bulit for telephone service are no longer adequate. This kind of growth will create thousands of jobs in the communications industry.

To understand what new systems we must create though, we must first understand how the information marketplace of the future will operate.

One helpful way is to think of the National Information Infrastructure as a network of highway-must like the Interstates begun in the 50 s.

There are highways carrying information rather than people or goods. And I'm not talking about just one eight-lane turnpike. I mean a collection of Interstates and freeder roads made up of different materials in the same way that roads can be concrete or macadam-or gravel. Some highways will be made up of fiber optics. Others will be built out of coaxial or wireless.

But - a key point - they must be and will be two way roads. These highways will be wider than today's technology permits. This is important because a television program contains more information than a telephone conversation; and because new uses of video and voice and computers will consist of even more information moving at even faster speeds. These are the computer equivalent of wide roads. They need wide roads. And these roads must go in both directions (Rohrer, 1997).

The mapping of the INTERNET IS A HIGHWAY metaphor is illustrated in detail in the following table (Table 2).

INTERNET IS A HIGHWAY 
TABLE 2:

AN EXAMPLE OF THE WORKING MECHANISM OF METAPHORS

\begin{tabular}{|l|l|}
\hline Source Domain & Target Domain \\
\hline Highway & Transmission pathways \\
\hline Space & Cyberspace \\
\hline Vehicles & Computers, telephones, etc \\
\hline Goods transported & Information \\
\hline Fuel & Electricity \\
\hline Drivers & Users \\
\hline Destinations & Information supply sites \\
\hline Journey & Downloading or uploading information \\
\hline Marketplace & Commercial information supplies \\
\hline Impediments to motion (roadblocks, etc) & Technological difficulties \\
\hline
\end{tabular}

In the above metaphor INTERNET IS A HIGHWAY, people can see that there is a cross-domain mapping that goes from the concrete source domain HIGHWAY, to the relatively abstract target domain INTERNET. Evidently, the mapping is not one to one, but a whole system is mapped onto another system. By the metaphor, people can understand and reason about INTERNET through their knowledge and experience about the HIGHWAY. Thanks to this metaphorical mapping, people's understanding about INTERNET is more profound and thorough.

So far, the paper offers a brief review of the conceptual metaphor theory. By discussing the nature and cognitive structure of the metaphors, people can have a better understanding about the language we use and encounter everyday. That is what we called: metaphors we live by.

\section{REFERENCES}

[1] Cameron, L. and Low, G. (eds.) (1999). Researching and Applying Metaphor, Cambridge: Cambridge University Press.

[2] Fuyin Li. (2004). Applied Cognitive Linguistics, Beijing: China Literature and History Press.

[3] Gibbs, R. W. (1994). The Poetics of Mind, Cambridge: Cambridge University Press.

[4] Hawkes, T. (1980). Metaphor, New York: Mathuen \& Co.Ltd.

[5] Johnson, M. (1987). The Body in the Mind: The Bodily Basis of Meaning, Imagination, and Reason, Chicago: University of Chicago Press.

[6] Johnson, M. and Lakoff, G. (2002). "Why cognitive linguistics requires embodied realism”, Cognitive Linguistics, 13 (3): 245-263.

[7] Lakoff, G. (1987). Women, Fire and Dangerous Things: What Categories Reveal about the Mind, Chicago: University of Chicago Press.

[8] Lakoff, G. (1993). "The contempory theory of metaphor", in Ortony, A. (2nd ed.) (1993) Metaphor and Thought, Cambridge: Cambridge University Press.

[9] Lakoff, G. and Johnson, M. (1980). Metaphors We Live By, Chicago and London: University of Chicago Press.

[10] Lakoff, G. and Johnson, M. (1999). Philophy in the Flesh: The Embodied Mind and Its Challenge to Western Thought, New York: Basic Books.

[11] Lakoff, G. and Turner, M. (1989). More than Cool Reason: A Field Guide to Poetic Metaphor, Chicago: University of Chicago Press.

[12] Rohrer, T. (1997). "Conceptual blending on the information highway: How metaphorical inferences work", in Liebert, W.-A., Redeker, G., Waugh, L. (eds.) (1997) Discourse and Perspective in Cognitive Linguistics, Amsterdam/ Philadelphia: John Benjamins Publishing Company.

[13] Steen, G. (1994). Understanding Metaphor in Literature, New York: Longman Group Limited.

[14] Sweetser, E. (1990). From Etymology to Pragmatics: The Mind-as-Body Metaphor in Semantics Structure and Semantic Change, Cambridge: Cambridge University Press.

[15] Taylor, J. R. (1995). Linguistic Categorization: Prototypes in Linguistics Theory (2nd ed.), Oxford: Oxford University Press.

[16] Turner, E. (1987). Death Is the Mother of Beauty: Mind, Metaphor, Criticism, Chicago: University of Chicago Press.

[17] Xiu Yu. (2011). "A Psycholinguistic Study of Metaphor Processing", Theory and Practice in Language Studies, 1(11), $1614-1617$.

[18] Xiu Yu. (2012). "On the Study of Synesthesia and Synesthetic Metaphor”, Journal of Language Teaching and Research, 3 (6): 1284-1289.

[19] Zonglin Chang. (2005). Cognitive Linguistics and Culture, Qingdao: Ocean University of China Press.

Xiu Yu was born in Qingdao, China in 1980. She received her M.A. degree in linguistics from Ocean University of China, China in 2007.

She is currently a teacher in the School of Foreign Languages, Qingdao University of Science \& Technology, Qingdao, China. Her research interests include psycholinguistics and cognitive linguistics.

Miss $\mathrm{Yu}$ is a member of the linguistic research center in the School of Foreign Languages, Qingdao University of Science \& Technology. 